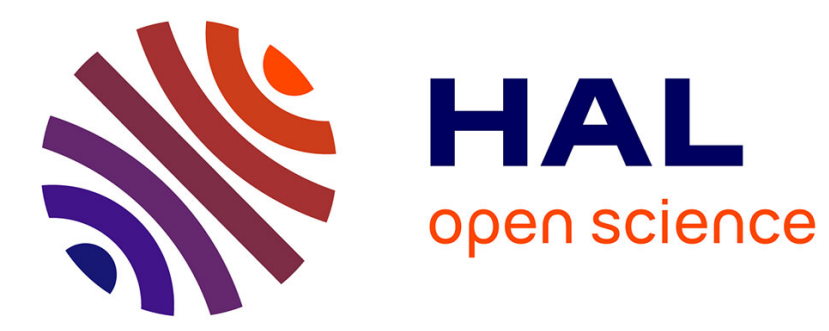

\title{
Aging-aware NaS battery model in a stochastic wind-storage simulation framework
}

Pierre Haessig, Bernard Multon, Hamid Ben Ahmed, Stéphane Lascaud, Lionel Jamy

\section{- To cite this version:}

Pierre Haessig, Bernard Multon, Hamid Ben Ahmed, Stéphane Lascaud, Lionel Jamy. Aging-aware NaS battery model in a stochastic wind-storage simulation framework. PowerTech 2013, Jun 2013, Grenoble, France. pp.1-6, 10.1109/PTC.2013.6652505 . hal-00863903

\section{HAL Id: hal-00863903 https://hal.science/hal-00863903}

Submitted on 19 Sep 2013

HAL is a multi-disciplinary open access archive for the deposit and dissemination of scientific research documents, whether they are published or not. The documents may come from teaching and research institutions in France or abroad, or from public or private research centers.
L'archive ouverte pluridisciplinaire HAL, est destinée au dépôt et à la diffusion de documents scientifiques de niveau recherche, publiés ou non, émanant des établissements d'enseignement et de recherche français ou étrangers, des laboratoires publics ou privés. 


\title{
Aging-aware NaS battery model in a stochastic wind-storage simulation framework
}

\author{
Pierre Haessig, Bernard Multon, Hamid Ben Ahmed; \\ Stéphane Lascaud, and Lionel Jamy ${ }^{\dagger}$
}

\begin{abstract}
Dispatchability of wind power is significantly increased by the availability of day-ahead production forecast. However, forecast errors prevent a wind farm operator from holding a firm production commitment. An energy storage system (ESS) connected to the wind farm is thus considered to reduce deviations from the commitment. We statistically assess the performance of the storage in a stochastic framework where day-ahead forecast errors are modeled with an autoregressive model. This stochastic model, fitted on prediction/production data from an actual wind farm captures the significant correlation along time of forecast errors, which severely impacts the ESS performance. A thermoelectrical model for Sodium Sulfur (NaS) batteries reproduces key characteristics of this technology including charging/discharging losses, statedependent electrical model and internal temperature variations. With help of a cost analysis which includes calendar and cycling aging, we show trade-offs in storage capacity sizing between deviation from commitment and storage costs due to energy losses and aging.
\end{abstract}

\section{Introduction}

In small islands which are not interconnected with a continental power grid, electricity production is often based on fossil fuels that are imported at a high cost. In such a context of expensive bulk electricity, wind turbines can be a profitable solution for electric power generation, wherever there is a strong enough

\footnotetext{
${ }^{*}$ P. Haessig, B. Multon, H. Ben Ahmed are with SATIE, ENS Cachan Bretagne, CNRS, UEB, av. Robert Schuman, 35170 Bruz, France (email pierre.haessig@bretagne.ens-cachan.fr)

${ }^{\dagger} \mathrm{S}$. Lascaud, Lionel Jamy are with the LME department of EDF R\&D, Écuelles, France
}

wind power potential. However, the small inertia of the grid in small islands makes it a challenge to stabilize the grid energy balance despite the high variability of wind power.

One way to compensate for the high variability of wind power is the deployment of wind power forecasting tools [1], with prediction horizons ranging from one hour to a few days. These tools, although based on advanced statistical regression techniques, cannot give perfect predictions. Their accuracy is qualified in the sense of either Root Mean Square Error (RMSE) or Mean Absolute Error (MAE), and is often about $5-15 \%$ of the installed power capacity [2]. Small islands, though, can suffer from larger prediction errors.

Electricity storage is another way to compensate for the variability of wind power [3]. It is best used together with wind power forecast where it can compensate forecast errors. A call for proposal was launched in November 2010 by the French Electricity Regulation Commission (CRE), for the installation of a new kind of wind generation system, that would be more reliable (that is, dispatchable) as well as provide some ancillary services to the grid by including an Energy Storage System.

\subsection{Increase in Wind Reliability with a Production Commitment}

The increase in production reliability is mainly based on a mechanism of day-ahead production commitment implemented by the wind-storage system of figure 1. Each day, before $5 \mathrm{pm}$, the wind production operator has to announce a power production schedule for each half-hour interval in the following day. This schedule $P_{\text {grid }}^{*}(t)$, based on a forecast $P_{\text {pre }}(t)$, is taken by the grid system operator as a firm production commitment. The actual power delivered to the grid $P_{\text {grid }}(t)$ should be kept as close as possible 


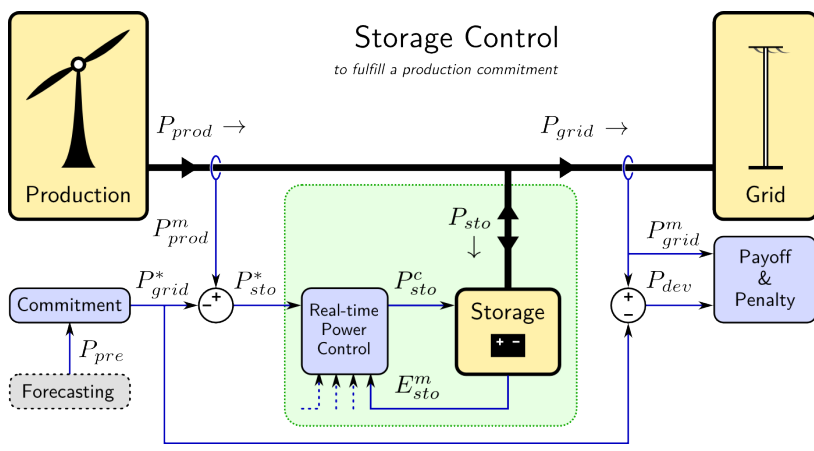

Figure 1: Wind-storage system controlled to fulfill a day-ahead commitment

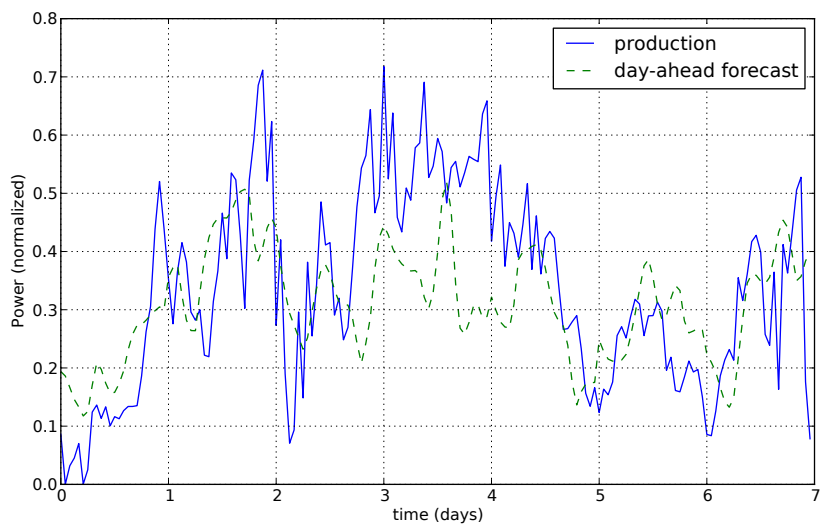

Figure 2: One week extract of production and dayahead prediction data, with a timestep of 1 hour.

to this commitment. This ability to hold the commitment depends heavily on the day-ahead forecast quality and we report a $16 \%$ RMS forecast error in field data from a wind farm in Guadeloupe, a French Caribbean island (see figure 2 for a week long data extract).

The purpose of this study is to analyze the performance of a Energy Storage System (ESS) in this context of a day-ahead production commitment. We build this ESS analysis on Sodium Sulfur (NaS) battery, a technology which is particularly suitable for grid scale storage, with examples of wind-storage system already commissioned with as much as 34 MW of storage power [4]. Also, a NaS battery has been installed in the French island of La Réunion since 2009 by EDF, the local electric utility. The battery ratings are $P_{\text {rated }}=1 \mathrm{MW}$ and $E_{\text {rated }}=$ 7.2 MWh.

A key element in the sizing study of an ESS is to have a model for the power request $P_{\text {sto }}^{*}$ which the storage is submitted to. With the hypothesis that the production commitment is chosen equal to the forecast $P_{\text {pre }}$ (though it may not be an optimal bidding strategy), this power request is actually equal to the forecast error. In a previous work [5], we analyze the dependence along time of day-ahead forecast errors. We highlight the high amount of correlation ( $80 \%$ ) between two successive hours and fit a simple stochastic model to field observations of dayahead forecast error. We show that this AR(1) model, from the ARMA family [6], can be used for stochastic simulation of an ESS to assess its performance (i.e. Monte Carlo approach).

In this previous work, the model for the ESS is a simple "energy integrator" with a saturation when storage is full or empty. This previous model is technology-agnostic and doesn't capture storage losses, aging, nor power exchange limitations. Now that we focus on a specific ESS technology, namely a $\mathrm{NaS}$ battery, we upgrade our stochastic simulations with a thermo-electrical ESS model that is way more realistic. In particular, this $\mathrm{NaS}$ battery model accounts for:

- electric losses from both Joule effect (internal " $R I^{2 "}$ losses) and AC-DC conversion (inverter losses).

- electric model changes caused by Depth of Discharge (DoD), temperature and Stage of Aging variations.

- temperature variations from heat flows imbalance.

- aging due charge/discharge cycling.

Although not implemented in the battery model, we also account for calendar aging in our subsequent cost analysis (section 4). We now describe the modeling of the battery (section 2) before turning to the stochastic simulations (section 3).

\section{Thermo-electrical modeling of a NaS battery}

NaS batteries, which emerged around 1980, are mainly produced by NGK Insulators, Ltd. for grid connected storage applications, including peak shaving and load leveling. Indeed, it is a hot battery, operating in the $300-350^{\circ} \mathrm{C}$ temperature range, for which the large scale effect is beneficial on reducing thermal losses.

Earlier descriptions of a NaS battery model include Hussien et al. [7] around 2005, based on cell data from Tokyo Electric Power Company (TEPCO), 


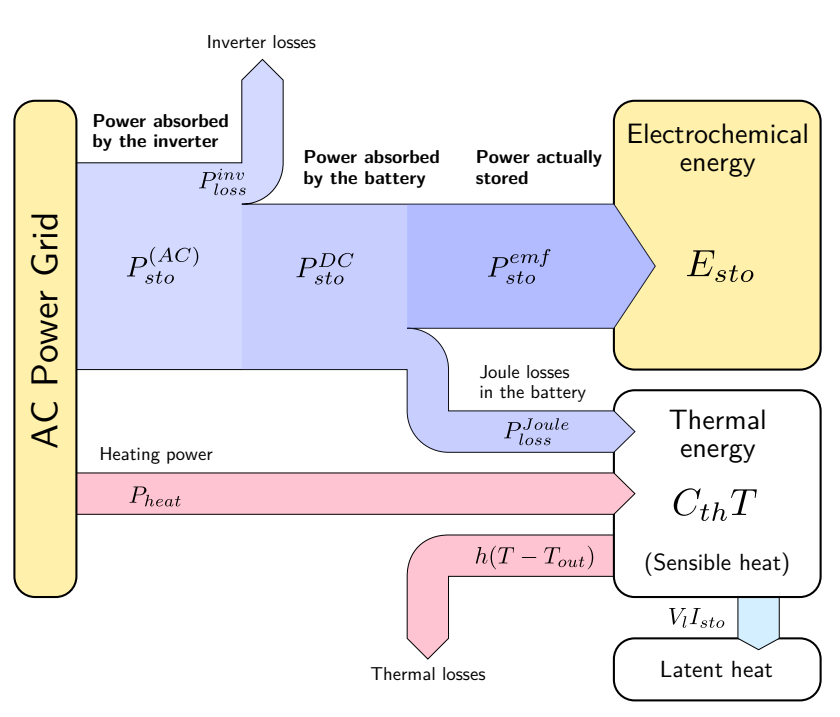

Figure 3: Energy flows (electrical and thermal) in the NaS battery model, represented during charging

NGK partner in the development of the NaS technology. Our model is similar in essence but using data from the manufacturer NGK (under a NonDisclosure Agreement with EDF) which may explain small variations in the numerical results. In addition, we give more details on the thermal modeling.

Figure 3 gives an overview of the of thermal and electrical energy flows in the model of the ESS and its environment. It shows how energy is transformed, stored, and partly lost in a NaS battery. We now describe this battery model, emphasizing the specific features of NaS technology both in its electrical behavior (section 2.2) and its thermal one (2.3).

\subsection{Description of the model structure}

We model a NaS battery composed of $N$ modules as shown in figure 4 . Those NGK modules are the basic building blocks of the ESS, with ratings of 350 $\mathrm{kWh} / 50 \mathrm{~kW}$. Each module is in turn made of a series-parallel arrangement of $n_{s} \times n_{p}=32 \times 12=$ $384 \mathrm{NaS}$ cells. A diagram of the internal structure of a NaS cell can be found in [7].

Our ESS model leverages this modular hardware structure by working internally at the scale of one module. Equal power sharing is assumed to perform the downscaling from the ESS to the module, i.e. $P_{\text {mod }}=P_{\text {sto }} / N$. Therefore, our model is fully sizable in terms of ratings by simply changing the number ${ }^{1}$

\footnotetext{
${ }^{1}$ For the convenience of our sizing study we assume that the integer $N$ can be an arbitrary real number which is acceptable if $N \gg 1$. It is the case in La Réunion island with $N=20$
}
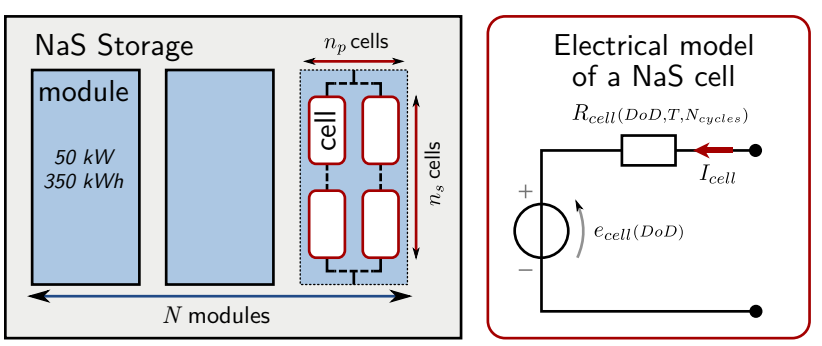

Figure 4: Description of the NaS battery assembly of modules and cells along with the electrical model of one cell

of modules $N$. Rated power and energy scale proportionally since the "E/P ratio" is fixed at 7.2 hours.

Electrical specifications like the electromotive force $e_{\text {cell }}$ and internal resistance $R_{\text {cell }}$ (see fig. 4 ) are specified for one $\mathrm{NaS}$ cell instead of a module. We thus scale these cell variables to the module level by assuming equal current sharing (i.e. $I_{\text {cell }}=I_{\bmod } / n_{p}$ ) and equal voltage sharing leading to

$e_{\text {mod }}=e_{\text {cell }} n_{s}$ and $R_{\text {mod }}=R_{\text {cell }} n_{s} / n_{p}$.

Our model is a state space model with 3 state variables:

- $D o D$ (in $\mathrm{Ah}$ ), the charge discharged from one $\mathrm{NaS}$ cell

- $N_{\text {cycles, }}$ the number "equivalent full cycles" which represents the State of Aging.

- $T$ (in ${ }^{\circ} \mathrm{C}$ ), the temperature of a NaS module

Their evolution is governed by equations (1), (2) and (3) which we now introduce.

\subsection{Electrical model of a battery cell}

Like Hussien et al., we model the NaS cell (see fig. 4) by a voltage source $e_{\text {cell }}$ accounting for the electromotive force (emf) and an internal resistance $R_{\text {cell }}$ which captures the output voltage drop. The accuracy (and complexity) of this Thévenin model stems from its dependence on all three state variables $\left(D o D, T, N_{\text {cycles }}\right)$.

Figure 5 illustrate the highly non-linear dependency of the resistance in the cell DoD and the temperature $T$. In addition, the resistance increases with cycling aging proportionally to $\sqrt{N_{\text {cycles }}}$. The emf is constant at $2.075 \mathrm{~V}$ for low $\mathrm{DoD}$ and then decays linearly [7].

\subsubsection{Cell DoD evolution}

DoD is governed by a charge counting equation, given here in discrete time (Euler explicit integration 


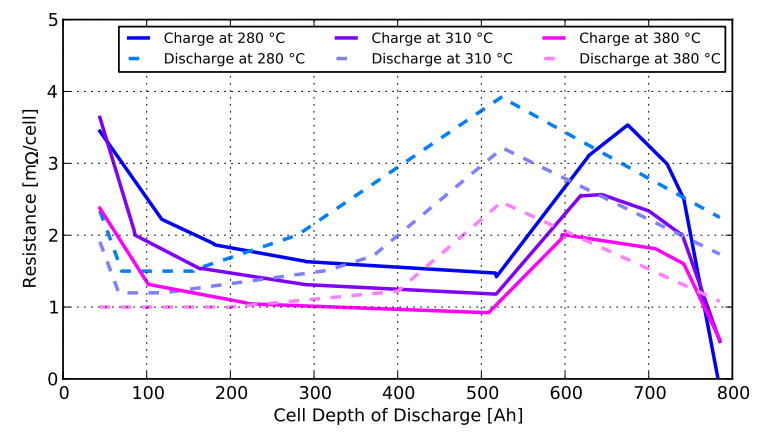

Figure 5: Internal resistance of a NaS battery cell, as a function of cell Depth of Discharge, module Temperature and charge/discharge state.

method). We choose the receptor convention, meaning that the cell current is positive when battery is charging:

$$
D o D(t+\Delta t)=D o D(t)-I_{\text {cell }}(t) . \Delta t
$$

\subsubsection{Cycling aging model}

Cycling is accounted as "equivalent full cycles" by summing the absolute value of charge exchanges ${ }^{2}$. This method is also named "Ah throughput" by Bindner et al. [8] and is of common use for lead-acid batteries:

$$
N_{\text {cycles }}(t+\Delta t)=N_{\text {cycles }}(t)+\frac{\left|I_{\text {cell }}(t)\right| \Delta t}{2 C_{\text {cell }}}
$$

where $C_{\text {cell }}$ is the NaS cell usable capacity ( $\left.600 \mathrm{Ah}\right)$. Because the cell resistance increases with the number of cycles $N_{\text {cycles, }}$, we can indeed speak of a "cycling aging" model. The effect of time in the absence of cycling (i.e. "calendar aging") is not captured in this model.

\subsection{Thermal model of a battery module}

Thermal modeling of a NaS battery is of prime importance because of the strong effect of the temperature on the internal resistance (fig. 5). The modeling of thermal energy flows (fig. 3) is done at the scale of the module which contains the 384 cells in a thermally insulated container filled with sand and weighs about 3 tons. Using a typical value of $1 \mathrm{~kJ} / \mathrm{K} / \mathrm{kg}$ for the average specific heat capacity,

\footnotetext{
${ }^{2}$ Counting is sometimes done for discharge current only. It is similar in essence to our counting by just removing the coefficient $1 / 2$ in eq (2). Counting the power instead of the current is another common variation.
}

we set the module thermal capacity $C_{t h}=3 \mathrm{MJ} / \mathrm{K}$, which is in good agreement with other observations.

The balance of thermal flows include Joule losses which generate heat as $R_{\text {mod }} I_{\text {mod }}^{2}$ and the reversible latent heat flow of the charge-discharge reaction. It is an exiting heat flow proportional to the electric current $V_{l} I_{\text {mod }}$ where the entropy term [9] $V_{l}$ is positive because the NaS battery charging $\left(I_{\text {mod }}>0\right)$ is an endothermic reaction while discharging $\left(I_{\text {mod }}<0\right)$ is exothermic. $V_{l} \approx 50 \mathrm{mV} \times n_{s}$ for a full battery and reaches $100 \mathrm{mV}$ when discharged [9]. There are also heat losses to the outside according to a linear model $\propto\left(T-T_{\text {out }}\right)$ and an embedded electric heater $P_{\text {heat }}$ to compensate for these losses. Combining all these thermal flows gives the thermal model of a NaS module:

$$
C_{t h} \frac{d T}{d t}=R_{\text {mod }} I_{\text {mod }}^{2}-V_{l} I_{\text {mod }}-P_{0} \frac{T-T_{\text {out }}}{T_{0}-T_{\text {out }}}+P_{\text {heat }}
$$

\subsection{Power-current relationships}

Although NaS electrical behavior is described by a voltage-current model, the model input is a power $P_{\text {sto. }}$. Therefore a power-to-current conversion is required to apply state equations (1) (2) and (3). For a given current $I_{m o d}$, the power absorbed by a module is:

$$
P_{\text {mod }}=e_{\text {mod }} I_{\text {mod }}+R_{\text {mod }} I_{\text {mod }}^{2}
$$

where the first term is the chemically stored power $\left(P_{\text {sto }}^{e m f}\right.$ on fig. 3 ) while the second term is Joule losses.

Solving for $I_{m o d}$ in (4), we get a power-to-current conversion formula:

$$
I_{\text {mod }}\left(P_{\text {mod }}\right)=\frac{P_{\text {mod }}}{e_{\text {mod }}} \frac{2}{1+\sqrt{1+4 R_{\text {mod }} P_{\text {mod }} / e_{\text {mod }}^{2}}}
$$

In order to evaluate the State of Energy of the ESS $\left(S o E=E_{\text {sto }} / E_{\text {rated }}\right)$, we also use a charge-to-energy conversion. The cell $D o D$ is converted into a stored energy $E_{c e l l}$ which is then scaled up to ESS level as $E_{\text {sto }}=\left(n_{s} n_{p} E_{\text {cell }}\right) \times N$.

\section{Stochastic NaS Storage Simulation Results}

For the purpose of assessing our simulation model in a stochastic framework, we feed our NaS model with a storage request $P_{\text {sto }}^{*}(k)$ modeled as the $\mathrm{AR}(1)$ process mentioned above: 

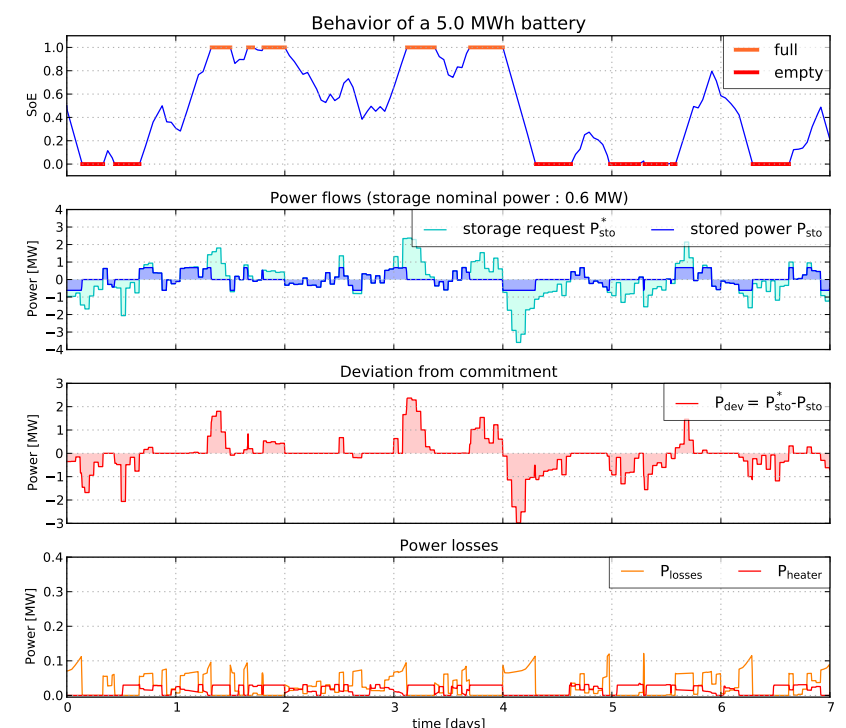

Figure 6: A week-long stochastic trajectory of a $5 \mathrm{MWh} \mathrm{NaS}$ storage system

$$
P_{\text {sto }}^{*}(k)=\phi P_{\text {sto }}^{*}(k-1)+\sigma_{P} \sqrt{1-\phi^{2}} \varepsilon(k)
$$

where $\{\varepsilon(k)\}$ is a sequence of independently and identically distributed (IID) zero-mean random variables of unitary variance. For our simulation, we use a Gaussian noise: $\varepsilon(k) \sim \mathcal{N}(0,1) . \quad \phi=0.8$ is the correlation between two successive timesteps (hours). $\sigma_{P}$ is the standard deviation of the process. Considering a wind farm with a rated power $P_{\text {nom }}$ of 10 MW and assuming $10 \%$ RMS error [2] we thus have $\sigma_{P}=1 \mathrm{MW}$.

As explained in previous work [5], this model does captures well the correlation structure of day-ahead forecast errors but does not account for an optimized bidding strategy (where $P_{\text {grid }}^{*}$ can be different from $\left.P_{\text {pre }}\right)$. It is suitable, though, to test our numerical $\mathrm{NaS}$ storage model. Only the resulting storage performance are sub-optimal.

\subsection{Example of a stochastic trajectory}

Figures 6-7 show an example of a week-long trajectory from our stochastic NaS storage simulation tool, fed by model (6) as an input to a $5 \mathrm{MWh}$ and a $15 \mathrm{MWh}$ battery. Simulation timestep $\Delta_{t}$ is 0.1 hour (except 1 hour for (6)).

One can see how the State of Energy (SoE) increases when there is a positive inflow of power $P_{\text {sto }}$ and decreases otherwise. For this article, we assume the use of a simple storage management policy which is "store the ideal storage request $P_{\text {sto }}^{*}$ whenever it is feasible". That is, $P_{\text {sto }}=P_{\text {sto }}^{*}$ at all times
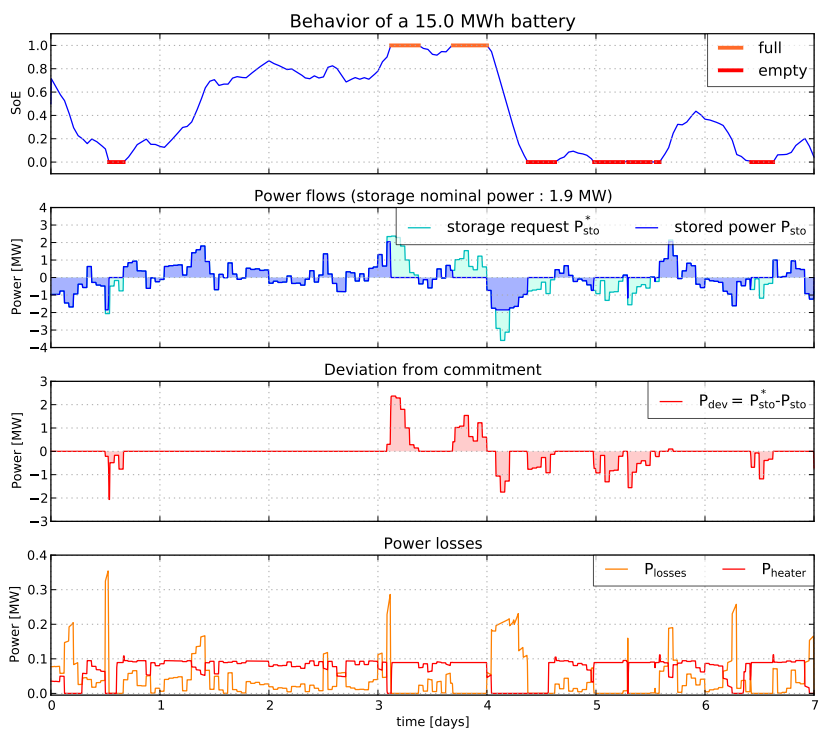

Figure 7: A week-long stochastic trajectory of a $15 \mathrm{MWh}$ NaS storage system

where the storage is neither empty nor full. When this condition is met, the deviation from schedule $P_{d e v}$ is zero. The lower panel shows both losses $P_{\text {losses }}$ (Joule and inverter ${ }^{3}$ ) and heating power consumption $P_{\text {heat }}$ of all $N$ modules.

\subsection{Stochastic simulation for performance assessment}

Simulation is repeated massively to collect sample trajectories of random time series such as those on figure 6 . These samples are used to statistically estimate performance metrics. We use the $\bar{X}$ notation for the mathematical expectation $\mathbb{E}[X]$ of any random variable $X$.

In figure 8 , we present these metrics for a range of 100 values of battery capacity, from 1 MWh to 50 MWh simulated for one month (30 days). For each of these capacity values, we collect $N_{\text {samp }}=1000$ independent sample trajectories (but vectorized in the same simulation loop) of 30 consecutive days on which to compute the following performance metrics:

- mean absolute deviation (MAD) from the commitment $\overline{\left|P_{d e v}\right|}$ (upper panel, in red)

- average electric losses $\bar{P}_{\text {losses }}$ and heating power consumption $\bar{P}_{\text {heat }}$ (middle panel)

- average aging, as capture by the equivalent cycle counting model (2) (lower panel)

${ }^{3}$ inverter losses (see fig. 3 ) are $5 \%$ of $\left|P_{\text {sto }}^{D C}\right|$, i.e. a $95 \%$ efficiency model. 

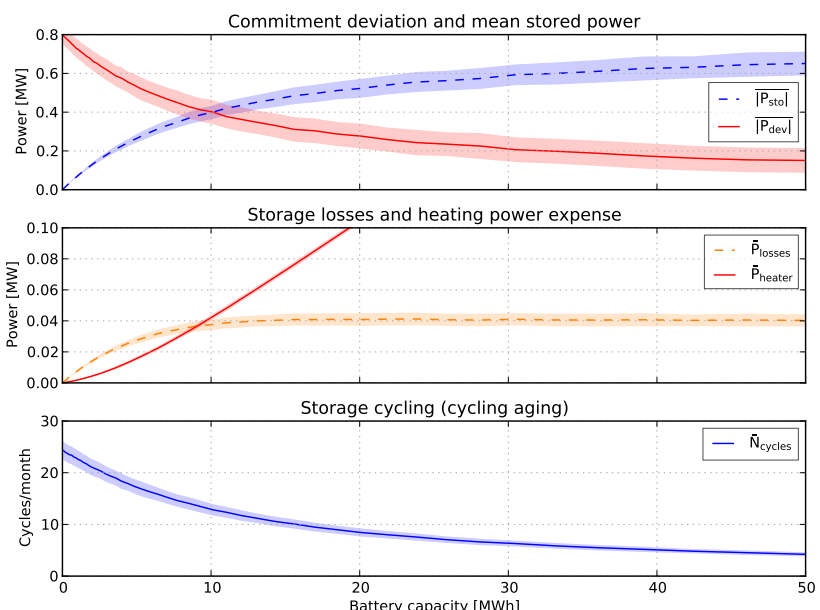

Figure 8: Parametric analysis of the NaS storage capacity sizing (with parameters $\phi=0.8$, $\sigma_{P}=1 \mathrm{MW}$ for the forecast error model (6))

We estimate these expectations by taking first the average along time on each of the $N_{\text {samp }}$ trajectories. Then we average on all samples to produce one point of the plotted lines. The filled color intervals show the standard deviation among the different trajectories (i.e. the inter-month variability), which is quite high for MAD but much lower for power losses or aging.

From figure 8, it is clear that the bigger the ESS capacity, the lower the deviation from commitment. Also, a bigger capacity generates less storage aging. However, thanks to the thermo-electrical model, one can see that a too big energy storage is detrimental to the overall system efficiency, mainly because of heating power consumption, which are asymptotically proportional to the ESS capacity.

Therefore, we now put a (monetary) weight on each of these metrics, to search for an optimal storage capacity.

\section{Cost analysis of the storage sizing}

\subsection{Cost model}

Our cost model is a sum of all storage costs accounting for losses and aging and a penalty cost for commitment deviation. We actually compute expected cost using expected values from the simulations.

We use the following cost parameters:

- battery calendar lifetime: $t_{\text {life }}=15$ years

- battery cycling lifetime: $N_{\text {life }}=5000$ full cycles
- battery unit cost : $c_{\text {batt }}=280 \mathrm{k} € / \mathrm{MWh}$

- electricity selling price : $c_{\text {elec }}=150 € / \mathrm{MWh}$ (to price lost and heating power)

- commitment deviation cost : $c_{d e v}=150 € / \mathrm{MWh}$ (expensive fee, but we discuss this choice later)

Storage cost $C_{\text {sto }}$ computed over a period of time $t$ is the sum of calendar, cycling, losses and heating costs:

$$
\begin{aligned}
C_{\text {sto }}(t) & =c_{\text {batt }} E_{\text {rated }}\left(\frac{\bar{N}_{\text {cycles }}(t)}{N_{\text {life }}}+\frac{t}{t_{\text {life }}}\right) \\
& +c_{\text {elec }}\left(\bar{P}_{\text {losses }}+\bar{P}_{\text {heat }}\right) t
\end{aligned}
$$

Cycling aging models are already used for storage sizing [10], but not always coupled to calendar aging as in (7).

Commitment deviation penalty $C_{d e v}$ is:

$$
C_{d e v}(t)=c_{d e v} \overline{\left|P_{d e v}\right|} t
$$

The total cost we wish to minimize is their sum:

$$
C_{\text {tot }}(t)=C_{s t o}(t)+C_{d e v}(t)
$$

Also, instead of computing these costs over an arbitrary period of time $t$, they are scaled in $€ / M W h$ by comparing them with the corresponding expected wind power production:

$$
\tilde{C}_{\text {sto }}=\frac{C_{\text {sto }}(t)}{\bar{P}_{\text {prod }} t}, \quad \tilde{C}_{\text {dev }}=\frac{C_{\text {dev }}(t)}{\bar{P}_{\text {prod }} t}, \quad \tilde{C}_{\text {tot }}=\frac{C_{\text {tot }}(t)}{\bar{P}_{\text {prod }} t}
$$

and supposing a $20 \%$ (1750 hours/year) load factor for our $P_{\text {nom }}=10 \mathrm{MW}$ farm, this gives an average production of $\bar{P}_{\text {prod }}=2 \mathrm{MW}$. Finally, the scaled total cost is:

$$
\begin{aligned}
\tilde{C}_{\text {tot }}=\frac{1}{\bar{P}_{\text {prod }}} & \left(c_{\text {batt }}\left(\frac{\overline{\left|P_{\text {sto }}\right|}}{2 N_{\text {life }}}+\frac{E_{\text {rated }}}{t_{\text {life }}}\right)\right. \\
& \left.+c_{\text {elec }}\left(\bar{P}_{\text {losses }}+\bar{P}_{\text {heat }}\right)+c_{\text {dev }} \mid \overline{P_{\text {dev }} \mid}\right)
\end{aligned}
$$

Costs, scaled by (10) are plotted on figure 9 as a function of the storage capacity. Detailed storage costs are depicted on the upper panel. It shows that calendar and cycling are the two biggest costs in the 0-10 MWh range while heating overtakes cycling beyond $20 \mathrm{MWh}$ (as expected from figure 8).

Adding the deviation penalty (lower panel) show that, at first, $\tilde{C}_{d e v}$ decreases faster than $\tilde{C}_{s t o}$ increases. This gives room for an optimal storage value of $E_{\text {rated }}^{*}=8.5 \mathrm{MWh}$ for a total cost of about $51 € / \mathrm{MWh}$ 

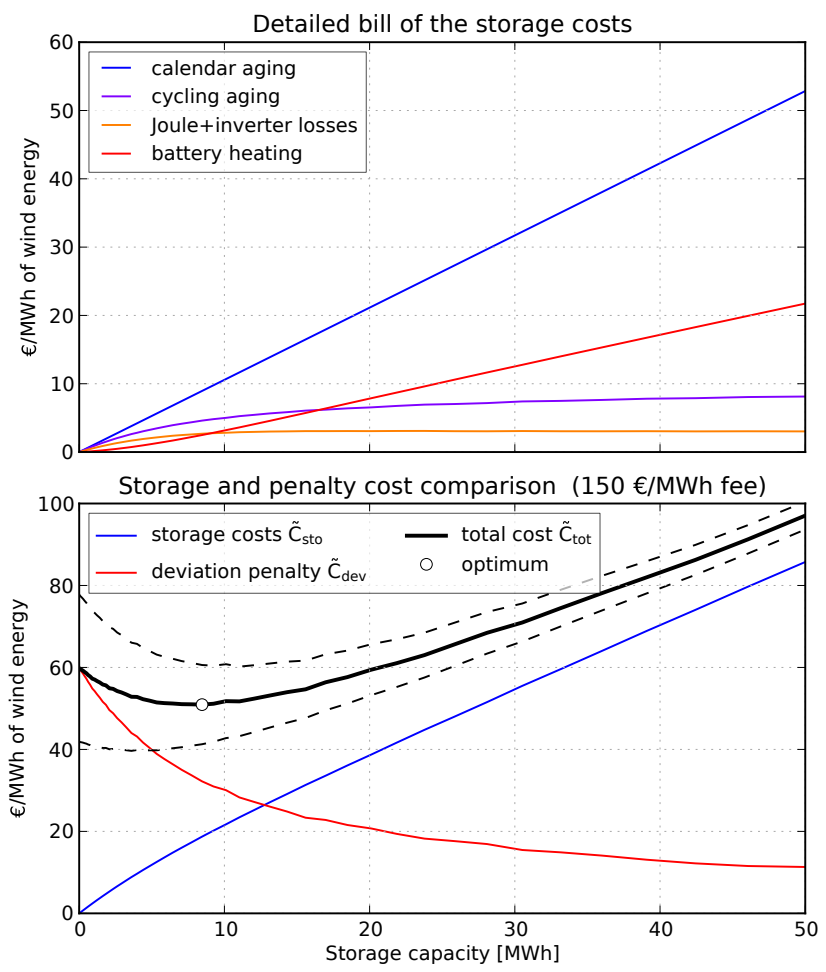

Figure 9: Cost analysis of the storage sizing, with sensitivity to a $\pm 30 \%$ variation of the deviation penalty fee (dashed lines)

(32 $€$ for penalty and $19 €$ for the storage). With this storage sizing, the MAD performance criterion $\overline{\left|P_{d e v}\right|}$ is reduced by almost $50 \%$ compared to the nostorage situation. This is a good though not tremendous improvement.

Finally, we want to emphasize that, though the penalty fees and storage costs may seem high, the wind operator is still profitable because post-storage earning is $c_{\text {elec }}-\tilde{C}_{\text {tot }} \approx 100 € / \mathrm{MWh}$ (which is to be further slit between wind farm amortization, operation cost and profit). This profitability comes from the hypothesis of a electricity selling price $c_{\text {elec }}=$ $150 € / \mathrm{MWh}$ which may look high but should be judged from an island grid perspective where coal baseload production is no less than $100 € / \mathrm{MWh}$.

\subsection{Sensitivity to the model parameters}

Among the many parameters that could be changed, we vary the two we perceive as the most uncertain.

\subsubsection{Penalty Cost}

We vary the penalty cost parameter $c_{d e v}$ by $\pm 30 \%$ because of the absence of shared guidelines to choose the penalty scheme. Total cost $\tilde{C}_{t o t}$ recomputed with altered penalty is plotted with dotted lines on figure 9. One can clearly observe a major effect of lowering the penalty price: the optimal capacity choice falls close to zero. Further trials show that below $c_{\text {dev }}=$ $70 € / \mathrm{MWh}$, the optimal cost lies at $E_{\text {rated }}=0$ (no storage) which means that the grid must bear all the forecast errors.

Therefore, for given storage costs and a given behavior of the forecast error, we identify a range of penalty cost which leads to reasonable decrease of the commitment deviation. In our case this range if about 100-200€/MWh.

\subsubsection{Stochastic input model}

The AR1 model (6) was introduced [5] to capture the main trend of forecast error interdependence along time. This dependence is entirely captured by the inter-hour correlation coefficient $\phi$ which we now vary for two reasons: the uncertainty coming from the AR1 model fitting procedure and because the AR1 captures the main trend but not the fine structure of forecast error interdependence [11].

Results from simulations with $\phi$ varied in the realistic 0.7-0.9 range show that any increase in $\phi$ leads to a $\tilde{C}_{d e v}\left(E_{\text {rated }}\right)$ curve which decreases more slowly. Therefore $\tilde{C}_{\text {tot }}$ gets flatter, the optimal capacity gets smaller and the commitment error reduction even smaller.

Because the storage behavior is quite sensitive to the behavior of the forecast error, an ongoing measurement campaign should help sharpen the forecast error model.

\section{Conclusion}

We report a thermo-electrical model for NaS battery storage, taking into account aging effect, used for a performance assessment in the context of a dayahead production commitment of wind power.

Our numerical model fits in a vectorized stochastic simulation framework which uses an autoregressive noise model as the storage request. Results from our stochastic simulations show the importance of thermal modeling of a NaS battery, especially to compute the heating power consumption, which can severely affect the overall system efficiency.

Our performance assessment based on Mean Absolute Deviation from commitment is translated into a cost analysis by means of a simple linear cost model which includes both calendar and cycling aging. Cost analysis shows that using a storage in the 
range of $P_{\text {nom }} \times 5-10 \mathrm{~h}$ is profitable when the deviation fee is quite high ( 100-200 €/MWh).

Finally, our results should not be taken as a real storage sizing. Indeed, the management of our windstorage system is sub-optimal because no commitment bidding strategy and no advance energy management policy are used. Future work on these strategies will enrich our wind-storage simulation framework.

\section{References}

[1] M. Ahlstrom, J. Blatchford, M. Davis, J. Duchesne, D. Edelson, U. Focken, D. Lew, C. Loutan, D. Maggio, M. Marquis, M. McMullen, K. Parks, K. Schuyler, J. Sharp, and D. Souder, "Atmospheric Pressure," IEEE Power Energy Mag., vol. 9, no. 6, pp. 97-107, nov.-dec. 2011.

[2] G. Giebel, R. Brownsword, G. N. Kariniotakis, M. Denhard, and C. Draxl, "The state-of-the-art in short-term prediction of wind power: A literature overview," ANEMOS.plus, Tech. Rep., 2011.

[3] "EPRI-DOE Handbook Supplement of Energy Storage for Grid Connected Wind Generation Applications ," EPRI, Tech. Rep. 1007189, Dec. 2004. [Online]. Available: http://my.epri.com/portal/server.pt? Abstract_id=000000000001008703

[4] N. Kawakami, Y. Iijima, Y. Sakanaka, M. Fukuhara, K. Ogawa, M. Bando, and T. Matsuda, "Development and field experiences of stabilization system using 34MW NAS batteries for a 51MW wind farm," in Industrial Electronics (ISIE), 2010 IEEE International Symposium on, july 2010, pp. 2371-2376.

[5] P. Haessig, B. Multon, H. Ben Ahmed, S. Lascaud, and P. Bondon, "Energy storage sizing for wind power: impact of the autocorrelation of day-ahead forecast errors ," Jan. 2013, submitted to Wind Energy. [Online]. Available: http://publications.pierreh.eu

[6] P. J. Brockwell and R. A. Davis, Time Series: Theory and Methods, second edition ed., ser. Springer Series in Statistics. Springer, 1991.

[7] Z. F. Hussien, L. W. Chung, M. Siam, and A. Ismail, "Modeling of Sodium Sulfur Battery for Power System Applications," Elektrika, vol. 9, no. 2, pp. 66-72, Dec. 2007. [Online].
Available: http://www.fke.utm.my/elektrika / dec07/paper11dec07.html

[8] H. Bindner, T. Cronin, P. Lundsager, J. F. Manwell, U. Abdulwahid, and I. Baring-Gould, "Lifetime Modelling of Lead Acid Batteries ," Risø National Laboratory, Tech. Rep., Apr. 2005.

[9] R. Knödler, "Thermal properties of sodiumsulphur cells," Journal of Applied Electrochemistry, vol. 14, pp. 39-46, Jan. 1984.

[10] Y. Ru, J. Kleissl, and S. Martinez, "Storage Size Determination for Grid-Connected Photovoltaic Systems," IEEE Trans. Sustain. Energy, vol. 4, no. 1, pp. 68-81, jan. 2013.

[11] P. Pinson and R. Girard, "Evaluating the quality of scenarios of short-term wind power generation," Applied Energy, vol. 96, no. 0, pp. 12-20, 2012. 